$\xi=1$

\title{
Genetic algorithm based ANN to predict compressive strength of siphon for different fiber volume fraction
}

\author{
Gottapu Santosh Kumar ${ }^{1 *}$, K. Rajasekhar ${ }^{1}$ \\ ${ }^{1}$ Department of Civil Engineering, Andhra University Engineering college,Visakhapatnam-530003, India \\ *Corresponding author E-mail: krsekhar08@gmail.com
}

\begin{abstract}
This paper presents the applicability of Genetic Algorithm based Artificial Neural Network (GAANN) for predicting Compressive strength of Slurry Infiltrated Fibrous Concrete (SIFCON) prepared with manufactured sand for different fibre volume fraction $(8 \%, 10 \%$ and $12 \%)$ as input vector. The network has been trained with data obtained from experimental work. The proposed GAANNs model is successfully used for predicting compressive strength of SIFCON (output vector) for various fibre volume fractions $(2 \%, 4 \%, 6 \%, 14 \%, 16 \%, 18 \%, 20 \%$ and $22 \%$ ) at 7 days, 28 days and 56 days of curing respectively. After successful learning GA based ANN model pre- dicted the compressive strength property satisfying all the constrains with an accuracy of about $85 \%$. The various stages involved in the development of genetic algorithm based neural network are addressed in depth in this paper.
\end{abstract}

Keywords: ANN; Genetic Algorithm; Manufactured Sand; MSE; SIFCON.

\section{Introduction}

Slurry-infiltrated fibrous concrete or mortar (SIFCON) is a relatively new material that can be considered as a special type of fiberreinforced concrete (FRC). In two aspects, however - namely, fiber content and the method of production-SIFCON is different from normal FRC. The fiber content of FRC generally varies from 1 to 3 percent by volume, but the fiber content of SIFCON varies between 5 and 20 percent. SIFCON is prepared by infiltrating cement slurry into a bed of fibers preplaced and packed tightly in the molds. Lankard invented a high strength material, which is known to be Slurry-infiltrated fibrous concrete (SIFCON). It has excellent mechanical properties with greater energy-absorption characteristics. In general, a fibre-reinforced concrete will contain $1-3 \%$ of fibres by volume, but SIFCON contains $6-20 \%$ of fibres. The composition of the matrix is the major difference between the two concretes. In SIFCON, the matrix is made-up of flowing mortar slurry as compared to aggregate concrete in normal fibre reinforced concrete. The casting is also different. In many cases, SIFCON is fabricated using a bed of pre-placed fibres with mortar slurry. Though SIFCON is a new material, it has found applications in areas of pavements repairs, safe vaults, repair of bridge structures, and defense structures because of its excellent energy absorption capacity. Slurry strength, fiber volume, fiber alignment, and type are the four main design factors that should be noted in a SIFCON product. The fiber volume depends on fibre type and vibration effort needed for proper compaction of cubes. The natural river

sand is the cheapest source of sand. But the excessive mining of the river bed has led to ecological imbalance in the society. Hence, the best replacement for this in the industry is the manufactured sand. It is also cost efficient as it contains nil impurities and waste materials. Traditionally, concrete is the widely used structural material for construction. Both strength and deformation characteristics of the specimens were studied. Superior characteristics of SIFCON were observed when compared to plain and normal FRM [1]. The percentage of fibres by volume can be approximately from 4 to $20 \%$ through the current practical range from 4 to $12 \%$ [2]. The proportions of cement and sand generally used for making SIFCON are $1: 1,1: 1.5$ or $1: 2$. The proposed mix proportion of cement slurry alone has some applications. The water cement ratio varies in-between 0.3 to 0.4 . Percentage of super plasticizers varies from 2 to $5 \%$ by weight of cement [3]. Serio Lai and Marzouk [1997] presented an ANN model predicting strength of building materials [4]. Yeh [1998] adopted ANN methods for modeling the strength of high performance concrete [5]. Guang et.al. [2000] developed ANN model for compressive strength of concrete using multilayer feed forward networks [6]. Raghunath Reddy [2001] has developed macro mechanical model for steel fibre reinforced concrete by ANN [7]. Sudarshana Rao and Chandrasekhara Reddy [2007] have developed ANN based macro mechanical model for slurry infiltrated fibrous concrete [8]. Sudarshaha Rao et.al. [2012] developed genetic algorithm based hybrid neural network model for predicting the ultimate flexural strength of ferrocement elements [9]. Vaishali et.al. [2013] developed Neural Network

model for predicting strength of high performance concrete [10]. Kasperkiewicz et al. (1995), Lai and Sera (1997) and Lee (2003) applied the NN for predicting properties of conventional concrete and high performance concretes [11-12]. Bai et al. (2003) developed neural network models that provide effective predicting capability with respect to the workability of concrete incorporating metakaolin (MK) and fly ash (FA) [13].Genetic Algorithm based Artificial Neural Networks are typical example of a modern interdisciplinary subject that helps solving various different engineering problems which could not be solved by the traditional modeling and statistical methods. Neural networks are capable of collecting, memorizing, analyzing and processing large number of data gained from some experiments or numerical analyses. Theyare an illustration of sophisticated modeling technique that can be used for solving many complex problems. The trained neural network serves as an analytical tool for qualified prognoses of theresults, for any input data, which were not included in the learning 
Process of the network. Their operation is reasonably simple and easy, yet correct and precise. Using the concept of the artificial neural networks along with Genetic algorithm and the results of the performed numerical analyses as input parameters, the prediction model for defining the compressive strength of

SIFCON for different percentage fibre fractions has been made.

\section{Experimental results}

Experiment was conducted on SIFCON mixes to determine the property of Compressive Strength. The prepared SIFCON specimen is shown in Fig. 1. The compressive strengths of the three specimens were tested using the Compression Testing Machine (CTM) of capacity $300 \mathrm{~T}$ in the laboratory as shown in Fig. 2. SIFCON-MS $8 \%$, SIFCON-MS $10 \%$ and SIFCON-MS $12 \%$ respectively refer to the average value of compressive strength of three specimens of SIFCON for 7 days, 28 days and 56 days re- spectively. The percentage increase in compressive strengths at 28 days and 56 days were compared with 7 days and illustrated in Table 1 .

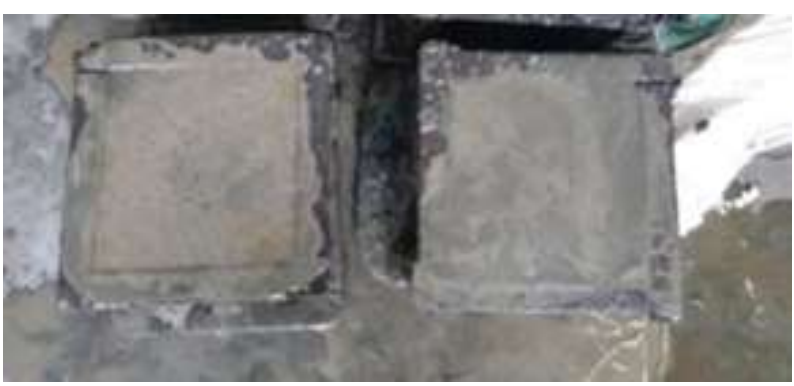

Fig. 1: Production of the SIFCON Specimens.

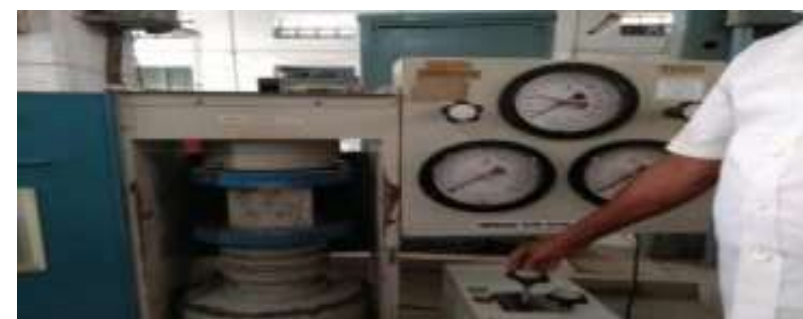

Fig. 2: Production and Test Procedure of the SIFCON Specimens.

Table 1: Compressive Strength of the SIFCON Specimens

\begin{tabular}{|c|c|c|c|c|c|c|c|}
\hline \multicolumn{2}{|c|}{ S.No.Mix } & \multicolumn{3}{|c|}{$\begin{array}{l}\text { Compressive strength } \\
(\mathrm{MPa})\end{array}$} & \multicolumn{3}{|c|}{$\begin{array}{l}\% \text { of increase or decrease in } \\
\text { Compressive strength } \\
\text { compared with } 7 \text { days }\end{array}$} \\
\hline & & $\begin{array}{l}7 \\
\text { days }\end{array}$ & $\begin{array}{l}28 \\
\text { days }\end{array}$ & $\begin{array}{l}56 \\
\text { days }\end{array}$ & $\begin{array}{l}7 \\
\text { days }\end{array}$ & $\begin{array}{l}28 \\
\text { days }\end{array}$ & $\begin{array}{l}56 \\
\text { days }\end{array}$ \\
\hline 1 & $\begin{array}{l}\text { SIFCON-MS } \\
8 \%\end{array}$ & 26.60 & 35.71 & 43.70 & - & 21.87 & 49.18 \\
\hline 2 & $\begin{array}{l}\text { SIFCON-MS } \\
10 \%\end{array}$ & 35.19 & 42.54 & 47.11 & - & 20.88 & 33.87 \\
\hline 3 & $\begin{array}{l}\text { SIFCON-MS } \\
12 \%\end{array}$ & 43.85 & 46.15 & 53.63 & - & 5.24 & 22.30 \\
\hline
\end{tabular}

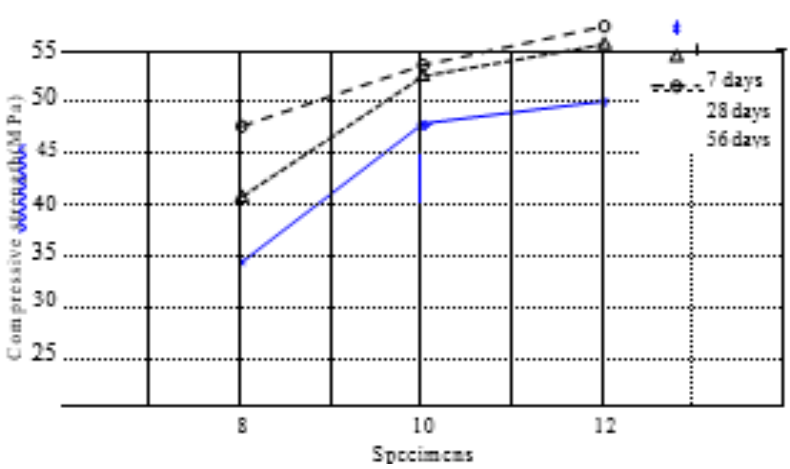

Fig. 3: Variation of Compression Test with Fiber Fraction.

\section{Genetic algorithm implementation for ANN training process}

Genetic Algorithm (GA) a generally used optimization method associated with high probability to reach a global minimum solution [16-17]. The property of Artificial Neural Network to learn, when combines with the property of Genetic Algorithm to con- verge to a global optimum, results to more competent algorithms. The method of implementing ANN with GA is discussed below.

After deciding upon the number of input, output nodes and hidden layer/nodes, the weight updating was done with GA. Let Xt defines a set of weights in the designed neural network at time instant $t$. These weights form the chromosomes of parent in the selected population. With the initialized population of weights, the output of the neural network was evaluated and found the fitness of individual parent based network output.

The parents from this initial population based on a specific cri- teria and fitness value for mating pool were selected. The output of the mating pool resulted in new population with a set of updat- ed weights, $\mathrm{Xt}+1$, whose fitness is further evaluated and the above process is repeated till desired fitness parent is generated. The parents obtained from required fitness were the solution or optimal trained weights for the designed network. Cross over (introducing a random weight as chromosome to a parent) operation was per- formed in order to convergent towards global optimum, and hence the rate of crossover should be very low. The procedure for im- plementation of GAANN for prediction of the compressive strengths is given below in steps and graphical representation of the proposed GANN implementation is shown in Fig. 4.

i) Fix the size of Input, Output and Hidden layer nodes.

ii) Determine the number of network weights in the network and create initial population. The chromosome size of individual parent in the.

iii) Population should be made equal to size of network weights.

iv) Initialize the chromosomes of the parents (i.e initialize the weights) randomly.

v) Evaluate the network output with every parent (i.e a set of weights) in the generated population.

vi) Determine the fitness of parents based on fitness function or objective function given in Eq.8.

vii) Based on the predefined criteria select parents for mating pool and based on the requirement crossover have to be done.

viii) The generated children from the mating pool will now become new set of population for next generation.

ix) Step ' $v$ ' is repeated if required fitness parent is not generated and when the required fitness is achieved, the iterations will be halt.

x) The final parent chromosomes, which hold weight information, are optimal weights for the network considered. 


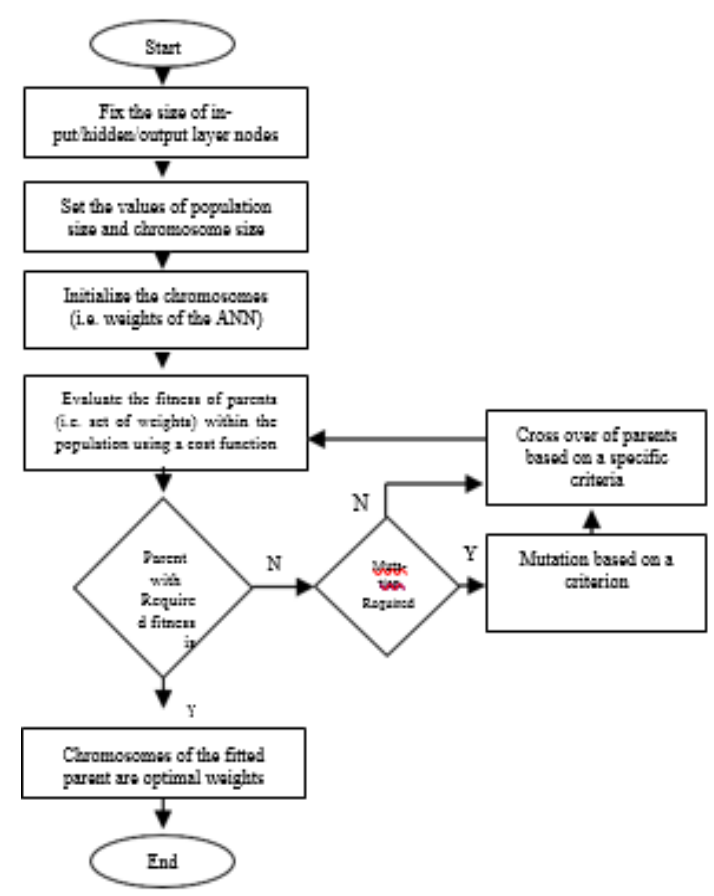

Fig. 4: GAANN Implementation Procedure.

The network construction was defined in terms of input and output vectors and the intermediate hidden layers ( $\mathrm{j}, \mathrm{k}, \mathrm{l}$ and $\mathrm{m}$ ). Once the input and output vectors were decided for the ANN de- sign, then a suitable formation was selected. In selection of hidden layers number and nodes in the layer was done by trial and error method. This trial and error method was continued until a perfect network configuration obtained. It was observed that the network with 15 neurons in each of [4] hidden layers $(\mathrm{j}, \mathrm{k}, \mathrm{l}$ and $\mathrm{m}$ ) is behav- ing well. Accordingly a configuration of (1-4-15-1) has been se- lected for this network model. The architecture is presented in Fig. 5.

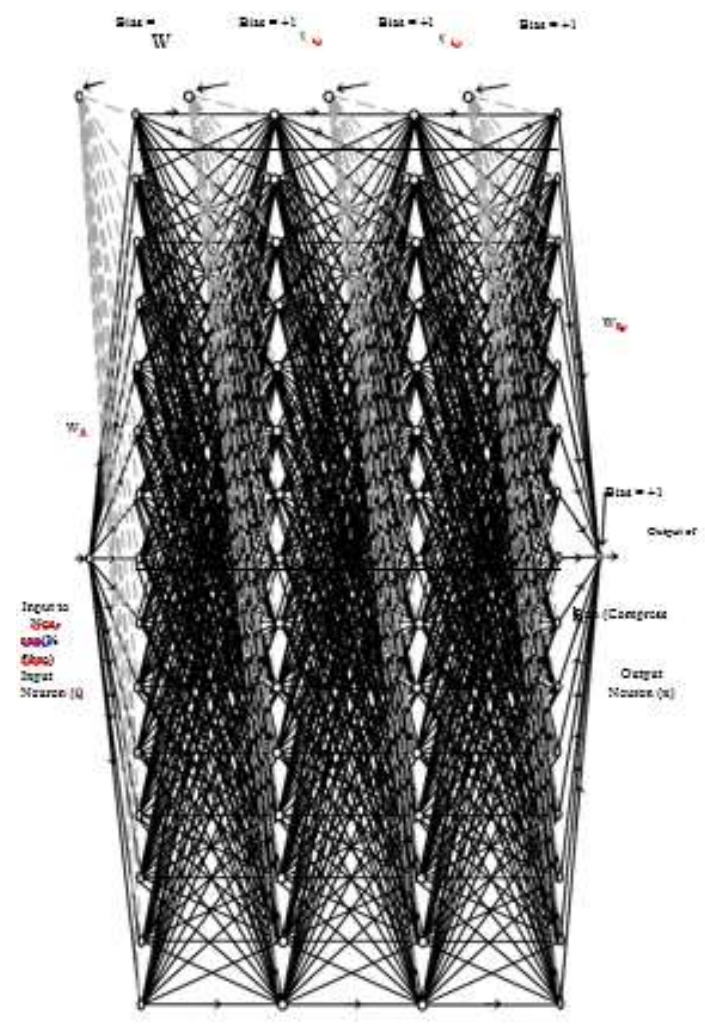

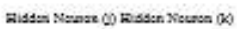

Fig. 5: Proposed ANN 1-4-15-1 Design with One Input, [4] Hidden Layers with 15 Neurons Each and One Output.

The compressive strength was predicted for $2 \%, 4 \%, 6 \%, 8 \%$,
$10 \%, 12 \%, 14 \%, 16 \%, 18 \%, 20 \%$ and $22 \%$ fibre volume fraction from the available values of compressive strength for $8 \%, 10 \%$ and $12 \%$ fibre volume fraction, which are obtained from testing the cube specimens in CTM of capacity 300T in laboratory. Pre- dicted values of compressive strengths of SIFCON for different fibre volume fractions were presented in Table 2.

Table 2: Predicted Values of Compressive Strengths of Sifcon for DifferENT Fiber Volume Fractions

\begin{tabular}{|c|c|c|c|c|c|c|}
\hline \multirow[t]{3}{*}{$\begin{array}{l}\text { Fiber } \\
\text { volume } \\
\text { fraction } \\
(\%) \\
\end{array}$} & \multicolumn{6}{|c|}{$\begin{array}{l}\text { Compressive strength of the SIFCON with manufactured sand } \\
\text { specimens predicted using the proposed GAANN and their } \\
\text { MSE values }\end{array}$} \\
\hline & 7 days & & 28 days & & 56 days & \\
\hline & Out- put & MSE & Out- put & MSE & Out- put & MSE \\
\hline 2 & 12.02 & 0.5648 & 14.57 & $\begin{array}{l}2.001 \\
9\end{array}$ & 32.10 & 1.2325 \\
\hline 4 & 15.65 & 0.9825 & 21.05 & $\begin{array}{l}0.995 \\
4\end{array}$ & 36.97 & 0.9135 \\
\hline 6 & 23.12 & $\begin{array}{l}12.360 \\
2\end{array}$ & 26.34 & $\begin{array}{l}1.741 \\
1\end{array}$ & 42.89 & 1.0046 \\
\hline 8 & 26.30 & 0.0156 & 35.16 & $\begin{array}{l}0.055 \\
2\end{array}$ & 45.39 & 0.4517 \\
\hline 10 & 35.85 & 0.2250 & 43.22 & $\begin{array}{l}4.167 \\
1\end{array}$ & 47.85 & 6.1414 \\
\hline 12 & 42.65 & 0.2561 & 46.24 & $\begin{array}{l}9.112 \\
1\end{array}$ & 52.89 & 0.5614 \\
\hline 14 & 48.54 & 0.9423 & 51.66 & $\begin{array}{l}3.465 \\
1\end{array}$ & 54.76 & 6.1411 \\
\hline 16 & 51.77 & 0.4519 & 54.12 & $\begin{array}{l}4.165 \\
4\end{array}$ & 55.81 & $\begin{array}{l}26.421 \\
4\end{array}$ \\
\hline 18 & 57.32 & 0.2354 & 59.03 & $\begin{array}{l}1.745 \\
1\end{array}$ & 59.11 & 0.7844 \\
\hline 20 & 54.96 & 6.2511 & 56.11 & $\begin{array}{l}2.412 \\
1\end{array}$ & 63.51 & 1.2254 \\
\hline 22 & 53.89 & 1.2377 & 55.32 & $\begin{array}{l}1.484 \\
9\end{array}$ & 60.91 & 1.3348 \\
\hline
\end{tabular}

From the Table 2, it was observed that the predicted values have accuracy of $85 \%$. The values of compressive strength ob- tained using GAANN has gradually increased as the fibre volume fraction increases. Increase in strength was obsered from $2 \%$ to $18 \%$ fibre volume fraction and when the fibre percent increased beyond 18 percent, there is a drop in the values of compressive strength. This decrease was observed in the compressive strength for both 7 days and 28 days specimens respectively. Whereas, for 56 days specimens, a decrease in the compressive strength was observed at $22 \%$ fibre volume fraction (Fig. 6).

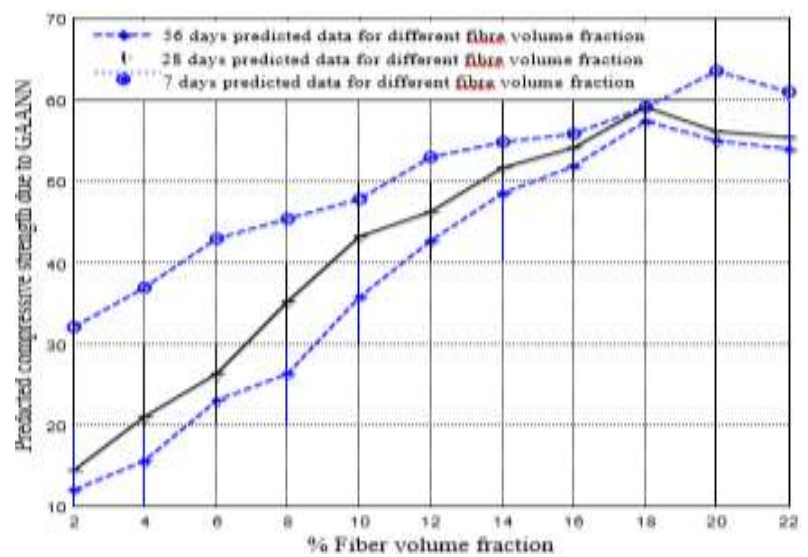

Fig. 6: Variation of Predicted Compressive Strengths of Proposed ANN with Fiber Volume Fraction.

The following conclusions were made from the developed GAANN moel for predicting the compressive strength of SIFCON.

- With increase in the fibre volume fraction from $2 \%$ to $18 \%$, there is a gradual increase in the compressive strength. When fibre percentage is increased beyond 18 percent, there is drop in the compressive strength at 7 and 28 days. 
- In the case of 56 days of curing, there is a gradual in- crease in the compressive strength obtained from $2 \%$ to $20 \%$ as the fiber volume fraction increases, and when fi- bre percent increased beyond $20 \%$, there is a drop in the compressive strength.

- $\quad$ For the case of 7 days curing, the estimated compressive strength values of the maximum and minimum MSEs were observed to be 9.3428 and 0.0 at $6 \%$ and $12 \%$ re- spectively. Whereas, the maximum and minimum MSEs observed were 7.3095 (at $12 \%$ ) and 0.0011 (at $8 \%$ ) for 28 days and 23.3801 (at $16 \%$ ) and 0.0002 (at $2 \%$ ) for 56 days.

In this paper, the application of GAANN model for predicting the Compressive Strength of SIFCON mixes with manufactured sand has been demonstrated the network model has been trained using 90 sets of samples obtained from the experimental results. The weights for network have been obtained using genetic algorithm The network could learn the prediction of Compressive Strength with just 433 iterations. After successful training GAANN model is able to predict Compressive Strength of SIFCON mixes with manufactured sand with an accuracy of about $85 \%$. Thus it is concluded the neural network model can serve as macro mechanical model for predicting strength properties of SIFCON

\section{References}

[1] Parameswaran VS (1990), Studies on Slurry Infiltrated Fibrous Concrete, Transportation Research Record 1382.

[2] Kuldeep Dagar (2012), Slurry infiltrated fibrous concrete, International Journal of Applied Engineering and Technology 2 ISSN: 2277-212X, 99-100.

[3] Arun Aniyan Thomas and Jeena Mathews (2014), Strength and Behaviour of SIFCON with Different Types of Fibres, International Journal of Civil Engineering and Technology 5, 25- 30.

[4] Serio Lai, and Marzouk (1997), Concrete strength prediction by means of Neural Network construction and building materials 11, 9398.

[5] Yeh IC (1998), Modeling of strength of high performance concrete using Artificial neural Networks, Journal of cement and concrete 28, 1797-1808.

[6] Guang NH, Zong WJ (2000), Prediction of compressive strength of concrete by neural networks, Journal of Cement Concrete Composites 16, 287-298.

[7] Raghunath Reddy T (2001), Development of a macro mechanica Neural Network model for steel fibre reinforced concrete, doctoral discussions, JNTU Hyderabad.

[8] Sudharsana Rao H, Subba Reddy PV, Vaishali G, Chandrasekhara Reddy T (2012), Development of Genetic Algorithm based hybrid Neural Network model for predicting the flexural strength of Ferrocement elements, International Journal of science and Technology 4 867-873.

[9] Kasperkiewics J, Racz J, Dubrawski A (1995), HPC strength prediction using ANN, Journal of Composite Civil Engineering 4, 279-284.

[10] Lai S, Sera M (1997), Concrete strength prediction by means of neural network, Journal of Construction and Building Materials 11, 9398.

[11] Lee SC (2003), Prediction of concrete strength using artificial neural networks, Journal of Engineering Structures 25, 849-857.

[12] Bai J, Wild S, Ware JA, Sabir BB (2003), using neural networks to predict workability of concrete incorporating metakolin and flyash, Journal of Advanced Engineering Software 34, 663-669. 